\title{
Mobile Phone Graphical User Interface (GUI) for Appliance Remote Control: An SMS-based Electronic Appliance Monitoring and Control System
}

\author{
Aaron Don M. Africa, Charmaine Rose S. Alcantara, Marc Erwin O. Lagula, \\ Adolfo A. Latina, Jr., and Charmaine D. Te \\ Department of Electronics and Communications Engineering \\ De La Salle University, Manila \\ 2401 Taft Ave., Malate, Manila 1004, Philippines, \\ aaron.africa@dlsu.edu.ph
}

\begin{abstract}
The home monitoring system is an effective way to prevent many household accidents that may occur whether we are aware or not. There are a lot of home control devices which were developed in the past. Take fire hazards for example, there are a lot of ways for a house fire to occur like overheating appliances. Fire imposes a big hazard in our homes but there is a device that was built to lessen the probability of this from occurring or at least lessen the damage done. The fire alarm works whenever there is enough smoke that goes in the detector. It will automatically make a sound to alarm the people inside the house, some home systems have a built-in sprinkler that work when the fire alarm activates preventing further property destruction. There are a lot of ways of designing a home control system but at these times, the design must be adaptable and adaptive to most people. Global System for Mobile Communication (GSM) is a means of wireless communication between people. It can also be used to communicate with devices such that it functions even if a user is not physically present in the vicinity of the device. GSM is the most adaptable medium since it has a further range of communication compared to Bluetooth and infrared. Moreover, it is also more accessible than Wi-Fi since it is more widely available. A home monitoring system interfaced with GSM poses a great advantage and convenience to the public. The user can be updated regarding the status ( $\mathrm{ON}$ or OFF) of his appliances which can prevent future damage. It will also be able to alarm the user of any irregular activities of the appliances immediately even if the user is at another place.
\end{abstract}

Key words: Global System for Mobile Communication, GUI, Home monitoring system, SMS.

\section{INTRODUCTION}

It is possible for people to leave their homes without remembering to turn off the appliances [1]. Over time, these appliances may overheat which may pose problems and cause accidents such as fire [2]. Therefore, the group proposes a thesis that will be a solution to this problem by building a device that will serve as a remote control for appliances. A GUI-based SMS network in a handheld device enables the user to double check the appliance's status, whenever the users go if there is a signal. Furthermore, to add more features aside from only getting the status of the appliances, the GUI has the capability to warn the user how long the appliances are on and if a short circuit occurs [3]. The maximum number of appliances that will be controlled is five and further specifications or restrictions will be explained in the scope and delimitations.

The GUI will be programmed as an application on a mobile phone. GUI, short for the graphical user interface, is a two-dimensional display that allows interaction between the electronic device and the user using images rather than text commands like in the research in: [4] . SMS will be used for sending and receiving of information. The GUI will be the platform for the device's status such that it comprises both the visual composition (design) and the codes for commands. The software is the most important part because it is the human-computer interaction and should be completely efficient to run the stored program [5]. The whole system will be further discussed in the description of the project.

There are numerous incidents of house fires that have happened these past few years and overheating of appliances is one of the main causes of fire accidents according to the Bureau of Fire Protection in the Philippines. Appliances overheat when people tend to leave the appliances turned on for a long time and this is inevitable for all of us to suddenly forget things. The main problem, aside from forgetting to turn off the appliances, is that there is no device in the market that enables to check its condition and gives alarm in case it is left "on" [6] . Although there are remote controls for appliances, but these can only be used within the premises and are restricted only for a short range [7].

As a solution to these problems, the group has decided to build a device that can be controlled via mobile phone that monitors 
the appliances and sends alarms to the users. The main purpose of developing this project is to remove the chance of a fire accident happening due to overheating appliances.

The study will be focused on programming an application-based graphical user interface (GUI) for appliance remote control. The application will be placed on a mobile phone using an Android Operating System like in the studies $[8,9]$. The application can control up to five appliances: flat iron, television set, electric fan, an incandescent lamp, and a cell phone charger. Aside from controlling the on/off state of the appliances, the application will monitor the status of the said appliances. Unlike the other related applications, the commands and control of the application will be transmitted via the GSM network.

The GUI-based Short Messaging Service (SMS) network between handheld devices develops another useful application with the mobile device [10]. It is a cost-effective solution for monitoring common home appliances because mobile phones are already a staple in society's daily living. In the Philippines, the number of mobile telephone subscribers has grown by more than 90 million according to the Mobile Communications - Market Overview and Forecasts report, and around 1.8 billion SMS messages are being sent every day in the Philippines. Generally, the group interfaced an application in a mobile phone to be able to have a wireless communication between the user and the appliance, and the group uses graphical user interface (GUI) over SMS to create and present information to and from mobile devices. It utilizes a programming language with SMS technology in everyday appliances [11]. Aside from the advancement, it brings to the current technology, it also benefits society. It makes use of a single device to operate five different devices which add comfort to the user, especially at times when the user is not at home [12]. It could prevent the overheating of appliances once left opened, which when not informed, could lead to a fire [13]

\section{DESIGN CONSIDERATIONS}

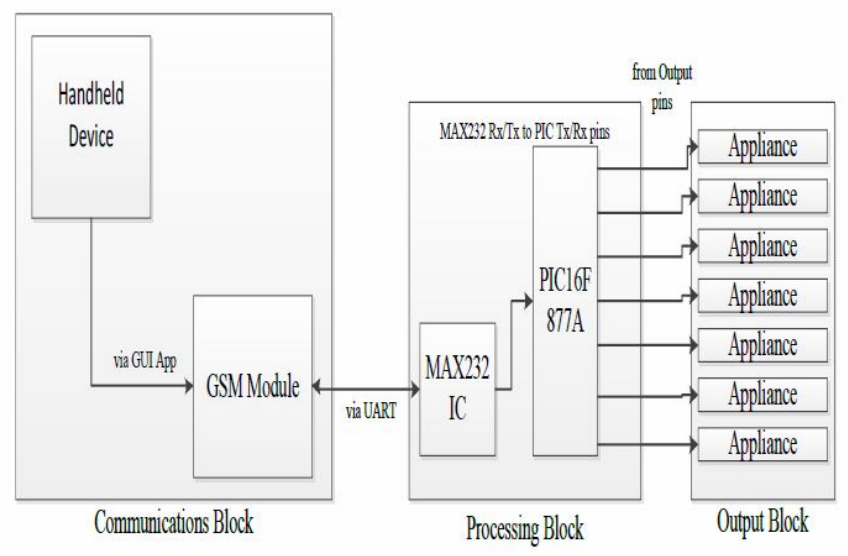

Figure 1: System Block Diagram

Figure 1 is the block diagram of the whole system. There are three blocks which comprise the system. These are namely the communications block, the processing block, and the output block. Its database design is like in the research of: [14]

The communication between the handheld device and the GSM Modem happens in the communications block. The GUI app installed within the handheld device has the capability of sending a message to the GSM Modem. The GSM Modem is able to receive the message because inside the modem, there is a SIM card holder. The selections in the GUI App will be programmed to send a distinct character to the number of the SIM card in the GSM Modem. These characters will have different functions depending on the program on the PIC microcontroller. The connection with the GSM Modem to the PIC microcontroller will be via UART communication using RS-232 cables. GSM Modems have built-in DB-9 pins that will be used to interface with the PIC18F4620. Here is the pin-out for the DB-9.

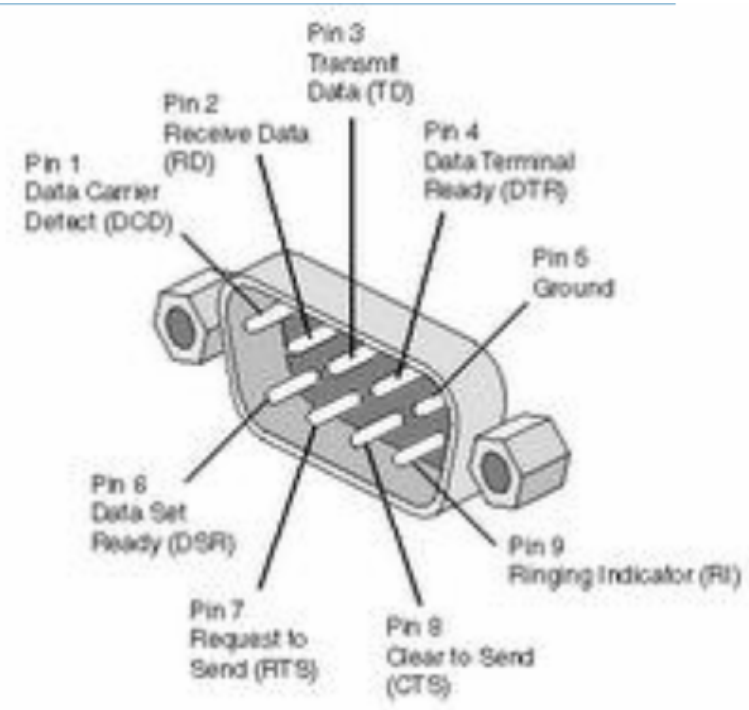

Figure 2: DB-9 Male Pin-out

Here, the processing of message received by the GSM Modem to readable data form for the PIC18F4620 happens. Each selection in the GUI App sends a specific character to the GSM Modem and is then sent to the PIC18F4620. These characters will then be stored in the PIC then read with a little delay, but the PIC is also capable of immediately reading the message received from the GSM Modem but storing the character first is a more effective method because when simultaneous messages occur, the PIC will be unable to read that fast and thus having the chance for the system to fail. Through storing the messages first, the PIC will output the commands one at a time. The MAX232 IC can convert TTL/CMOS logic level into RS232 logic level, which is important since RS232 serial cable will be used for the communication of the GSM Modem and the PIC18F4620. Figure 2 shows a simple connection of the GSM Modem to the MAX232 IC. For Optimization purposes the Rough Set Theory can be used just like in the researches of: $[15,16,17]$. 


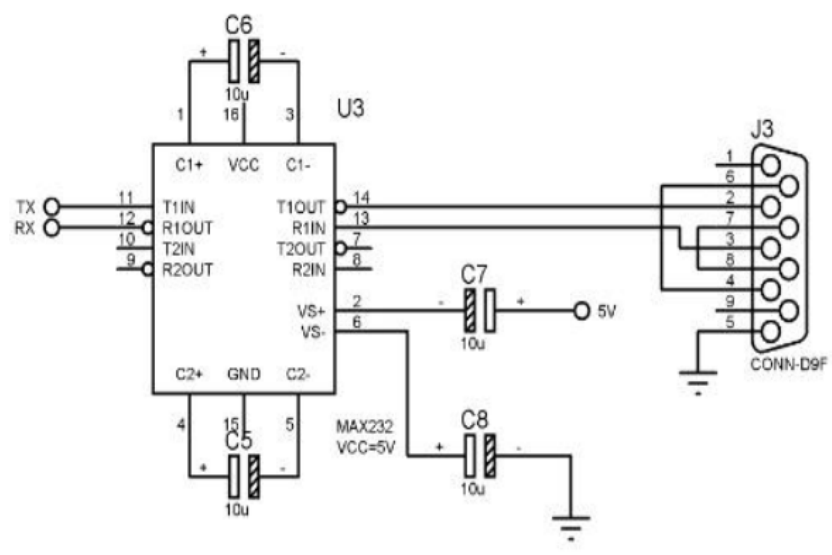

Figure 3: MAX232 IC to DB-9 Connection

The MAX232 IC pin Rx and Tx are connected to the Tx and $\mathrm{Rx}$ pin of the PIC18F4620. When the MAX232 IC is to transmit data, it is to be received by the PIC18F4620. Same goes when the PIC18F4620 is the one to transmit data, the MAX232IC will be receiving it. Here is a sample DB-9 to MAX232 to PIC18F4620 connection. In this connection the Logic Scoring of Preference can be used [18] but the database configuration of $[19,20]$ must be followed.

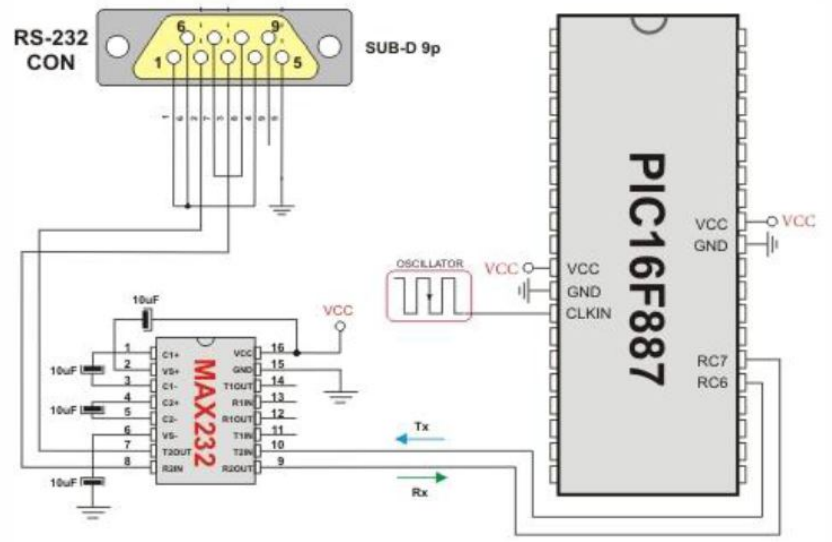

Figure 4: DB-9 to PIC18F4620 Interface using RS232 Serial Cable and MAX232IC

Here is where the data are properly sent and processed into commands executed by the PIC18F4620. The output block does what it is programmed to do. The output block consists of the appliances plugged in the sockets where relays will be used to determine which socket will be supplied and which are not. The relays are normally open so no current will flow to the appliance when they are initially plugged in but when the relays are supplied with sufficient voltage, they will close and thus, letting current flow into the sockets and up to the appliances. The relay supplies will be coming from the output ports of the PIC18F4620. For network security the researches in $[21,22,23]$ can be used.

\section{DATA AND RESULTS}

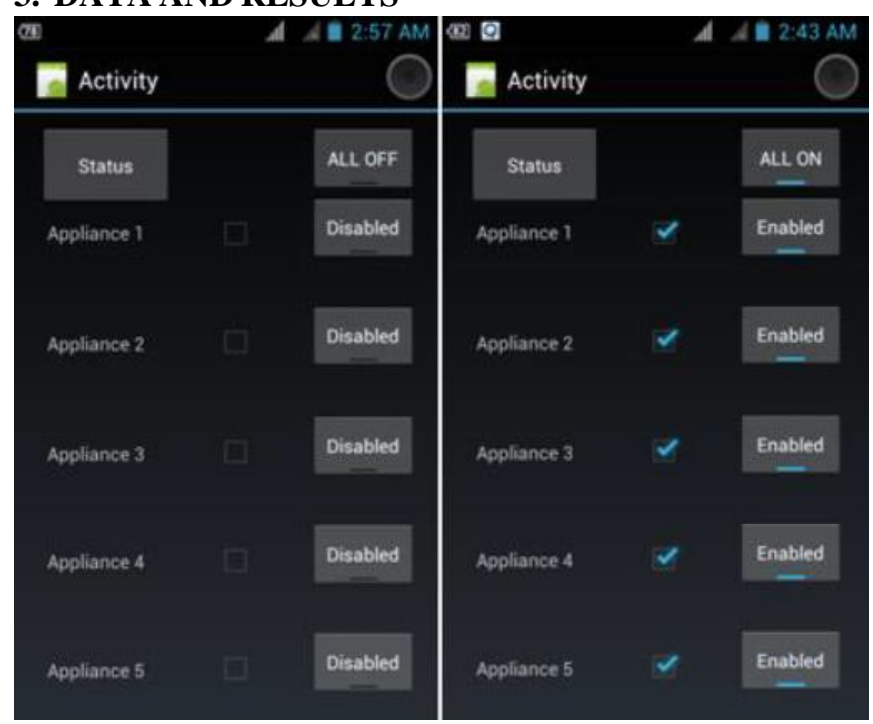

Figure 5: Output Android GUI Screenshot

Figure 5 shows the Android application menu options. The checkbox, when clicked, will send a corresponding SMS message to the GSM modem, either turning on or off any appliance. The ALL ON/. ALL OFF button will send a command that will turn on or turn off all the appliances at the same time. The status button, when clicked, will send an SMS message that will ask the microcontroller on which appliance/s is turned on and which is turned off. At the right side of every checkbox, there the Enabled/Disabled button, which will activate or deactivate the timer sequence for overheating. For this type of configuration Clustering Methods and Fuzzy Logic can be used [24,25] and so is Spatial Imaging algorithms and ANN [26,27].

Table 1: Android Application and Corresponding Message

\begin{tabular}{|c|c|c|c|c|}
\hline Android App Selection & Corresponding. Nessage & & & \\
\hline & 0N & OFF & TURN ALL 0N & TURN ALL 0FF \\
\hline Applinuce 1 & A & F & K & L \\
\hline Appliance 2 & B & G & K & L \\
\hline Appliance 3 & C & H & K & L \\
\hline Appliance 4 & D & I & K & L \\
\hline Appliance 5 & E & J & K & L \\
& & & & \\
\hline
\end{tabular}


Table 1. shows the Android application menu options and its corresponding message to be sent to the GSM module when the option, which is in form of a checkbox, has been ticked. Each option and function has a specific letter to be sent to avoid further confusion in the reading and flow of the GSM Modem.

Table 2: PIC18F4620 Output in Pins

\begin{tabular}{|c|c|c|}
\hline Message Read & Output Voltage & Pin Number \\
\hline A & $5 \mathrm{~V}$ & 34 \\
\hline B & $5 \mathrm{~V}$ & 35 \\
\hline $\mathrm{C}$ & $5 \mathrm{~V}$ & 36 \\
\hline $\mathrm{D}$ & $5 \mathrm{~V}$ & 37 \\
\hline E & $5 \mathrm{~V}$ & 38 \\
\hline $\mathrm{F}$ & $0 \mathrm{~V}$ & 34 \\
\hline $\mathrm{G}$ & $0 \mathrm{~V}$ & 35 \\
\hline $\mathrm{H}$ & $0 \mathrm{~V}$ & 36 \\
\hline I & $0 \mathrm{~V}$ & 37 \\
\hline $\mathrm{J}$ & OV & 38 \\
\hline $\mathrm{K}$ & $5 \mathrm{~V}$ & Pins $34-38$ \\
\hline L & OV & Pins $34-38$ \\
\hline
\end{tabular}

Table 2 shows the response of the PIC18F4620 when the message from the Android app is received. The corresponding pins and output voltages at the pins are also indicated for convenience.

Table 3: Extension cord - Relay Circuit Output Comparison

\begin{tabular}{|l|l|l|l|}
\hline $\begin{array}{l}\text { Relay Outlet } \\
\text { Voltage } \\
\text { Comparison }\end{array}$ & $\begin{array}{l}\text { Relay Outlet } \\
\text { Voltage }\end{array}$ & \\
\hline ON & $230 \mathrm{Vac}$ & $0 \mathrm{~N}$ & $230 \mathrm{Vac}$ \\
\hline OFF & $7.09 \mathrm{Vac}$ & OFF & $9.08 \mathrm{Vac}$ \\
\hline
\end{tabular}

Table 3 shows the comparison of the logic high and low of a regular extension line and the prototype. Both the prototype and the extension line produced 230Vac when at logic high but in logic low, the regular extension line, which is considered the ideal, produced a lower value than what the prototype has produced. The group observed the difference in the logic low voltage in the wire used to connect the step-down transformer $(220 \mathrm{Vac}$ to $12 \mathrm{Vdc}$ ) and to the relay circuit board. The resistivity of the wire was taken into action but as much as the group wanted to meet the ideal case, the wire will have to be too short to move the board around the prototype or too thin for the $220 \mathrm{Vac}$ to flow.

Table 4: Reliability Testing with respect to Distance

\begin{tabular}{|c|c|c|}
\hline Distance Testing & $\begin{array}{c}\text { UNDER HIGH } \\
\text { RECEPTION(3-4 } \\
\text { bars) }\end{array}$ & $\begin{array}{c}\text { UNDER LOW } \\
\text { RECEPTION(0-2 } \\
\text { bars) }\end{array}$ \\
\hline Distance & $\begin{array}{c}\text { Time Before } \\
\text { Message Received } \\
\text { (s) }\end{array}$ & $\begin{array}{c}\text { Time Before } \\
\text { Message Received } \\
\text { (s) }\end{array}$ \\
\hline Beside Prototype & 14.8 & 81.3 \\
\hline $5 \mathrm{ml}$ & 16.1 & 63.3 \\
\hline $10 \mathrm{~m}$ & 18.5 & 51.2 \\
\hline $15 \mathrm{~m}$ & 20.6 & 108.7 \\
\hline 20m & 21.2 & 51.1 \\
\hline Average Time $=$ & 17.98 & 72.95 \\
\hline
\end{tabular}

Table 4 shows the distance testing and reliability testing under different receptions of the GSM Module. It can be observed that under high reception, the distance is just a minor factor in the time before receiving the message, just like in regular SMS conversation. Some distances may be greater, but the time difference is not significantly large. Under low reception, the GSM Module had a hard time receiving the message. Some messages were not even able to be received. This just shows that the prototype may likely be unreliable under a low reception area. 
Table 5: Outlet 1 Appliance (Charger) Testing

\begin{tabular}{|c|c|c|}
\hline Outlet 1 Testing & Charger & \\
\hline Outlet 1 Testing & Charger & \\
\hline & $\begin{array}{c}\text { ON Condition } \\
\text { ('A') }\end{array}$ & $\begin{array}{c}\text { OFF Condition } \\
\text { ('F') }\end{array}$ \\
\hline Trials & Time (secs) & Time(secs) \\
\hline 1 & 13.2 & 5.2 \\
\hline 2 & 15.7 & 5.1 \\
\hline 3 & 14.4 & 5.6 \\
\hline 4 & 15.1 & 6.3 \\
\hline 5 & 13.5 & 5.6 \\
\hline 6 & 12.2 & 5.8 \\
\hline 7 & 16.7 & 7.1 \\
\hline 8 & 14.2 & 6.5 \\
\hline 9 & 14.6 & 5.9 \\
\hline 10 & 15.6 & 6.0 \\
\hline
\end{tabular}

Table 6: Outlet 1 Appliance (Lamp) Testing

\begin{tabular}{|c|c|c|}
\hline $\begin{array}{c}\text { Outlet 1 } \\
\text { Tessing }\end{array}$ & Lamp & \\
\hline & $\begin{array}{c}\text { ON Condition } \\
\text { ('A') }\end{array}$ & $\begin{array}{c}\text { OFF Condition } \\
\text { ('F') }\end{array}$ \\
\hline Trials & Time(secs) & Time(secs) \\
\hline 1 & 14.2 & 6.1 \\
\hline 2 & 13.4 & 5.2 \\
\hline 3 & 15.6 & 5.2 \\
\hline 4 & 14.1 & 5.6 \\
\hline 5 & 16.7 & 5.1 \\
\hline 6 & 15.2 & 6.7 \\
\hline 7 & 14.6 & 6.1 \\
\hline 8 & 12.8 & 6.6 \\
\hline 9 & 13.0 & 5.6 \\
\hline 10 & 16.5 & 6.7 \\
\hline Average Time & 14.6 & $\mathbf{5 . 9}$ \\
\hline
\end{tabular}

Table 7: Outlet 1 Appliance (Flat Iron) Testing

\begin{tabular}{|c|c|c|}
\hline Outlet 1 Testing & Iron & \\
\hline Trials & $\begin{array}{c}\text { ON Condition } \\
\text { ('A') }\end{array}$ & $\begin{array}{c}\text { OFF Condition } \\
\text { ('F') }\end{array}$ \\
\hline 1 & 14.5 & 5.0 \\
\hline 2 & 14.2 & 5.0 \\
\hline 3 & 13.2 & 5.4 \\
\hline 4 & 13.5 & 5.6 \\
\hline 5 & 13.7 & 5.7 \\
\hline 6 & 14.5 & 5.1 \\
\hline 7 & 16.1 & 6.1 \\
\hline 8 & 15.8 & 6.2 \\
\hline 9 & 13.1 & 5.2 \\
\hline 10 & 16.2 & 5.7 \\
\hline Average Time & 14.5 & $\mathbf{5 . 5}$ \\
\hline
\end{tabular}

Table 8: Outlet 1 Appliance (Electric Fan) Testing

\begin{tabular}{|c|c|c|}
\hline Outlet 1 Testing & \begin{tabular}{c} 
Electric Fan \\
\hline $\begin{array}{c}\text { ON Condition } \\
\text { ('A') }\end{array}$
\end{tabular} & $\begin{array}{c}\text { OFF Condition } \\
\text { ('F') }\end{array}$ \\
\hline Trials & Time (secs) & Time(secs) \\
\hline 1 & 14.1 & 5.6 \\
\hline 2 & 13.4 & 5.7 \\
\hline 3 & 15.1 & 5.1 \\
\hline 4 & 14.5 & 5.2 \\
\hline 5 & 13.2 & 5.7 \\
\hline 6 & 13.6 & 5.1 \\
\hline 7 & 16.1 & 6.0 \\
\hline 8 & 14.7 & 6.1 \\
\hline 9 & 13.9 & 5.2 \\
\hline 10 & 15.1 & 5.0 \\
\hline Average Time & 14.4 & $\mathbf{5 . 5}$ \\
\hline
\end{tabular}


Table 9: Outlet 1 Appliance (Television) Testing

\begin{tabular}{|c|c|c|}
\hline $\begin{array}{l}\text { Outlet } 1 \\
\text { Testing }\end{array}$ & Television & \\
\hline & $\begin{array}{l}\text { ON Condition } \\
\text { ('A') }\end{array}$ & $\begin{array}{l}\text { OFF Condition } \\
\left(\mathrm{F}^{\prime}\right)\end{array}$ \\
\hline Trials & Time (secs) & Time(secs) \\
\hline 1 & 14.2 & 5.7 \\
\hline 2 & 14.6 & 5.1 \\
\hline 3 & 14.6 & 5.2 \\
\hline 4 & 15.1 & 6.1 \\
\hline 5 & 13.2 & 5.7 \\
\hline 6 & 13.7 & 5.6 \\
\hline 7 & 15.1 & 5.0 \\
\hline 8 & 14.6 & 5.2 \\
\hline 9 & 12.8 & 5.2 \\
\hline 10 & 13.9 & 5.7 \\
\hline Average Time & 14.2 & 5.5 \\
\hline
\end{tabular}

Tables 1 up to 9 shows the time it takes for OUTLET1 to turn $\mathrm{ON}$ and $\mathrm{OFF}$. The interfacing initialization process was taken into consideration under the $\mathrm{ON}$ condition. The OFF-condition time is taken when the outlet has turned ON beforehand. It was tested ten times to ensure reliability between the interfacing of the devices. Variable power consuming appliances were used for testing whether the device can withstand and turn it $\mathrm{ON}$ despite the difference in the supply it requires. (Charger consumes less power than flat iron). Appliance current testing can replicate the test of these 3 papers [28,29,30].

Table 10: Outlet 2 Appliance (Charger) Testing .

\begin{tabular}{|c|c|c|}
\hline Outlet 2 Testing & Charger & \\
\hline & $\begin{array}{c}\text { ONCondition } \\
\left(\mathrm{B}^{\prime}\right)\end{array}$ & $\begin{array}{c}\text { OFF Condition } \\
\left(\mathrm{G}^{\prime}\right)\end{array}$ \\
\hline Trials & Time (secs) & Time(secs) \\
\hline 1 & 13.5 & 5.6 \\
\hline 2 & 15.1 & 5.1 \\
\hline 3 & 14.5 & 5.7 \\
\hline 4 & 14.7 & 5.0 \\
\hline 5 & 15.1 & 5.9 \\
\hline
\end{tabular}

\begin{tabular}{|c|c|c|}
\hline 6 & 13.9 & 6.1 \\
\hline 7 & 12.5 & 6.2 \\
\hline 8 & 14.1 & 5.1 \\
\hline 9 & 14.8 & 5.0 \\
\hline 10 & 14.8 & 5.4 \\
\hline Average Time & 14.3 & $\mathbf{5 . 5}$ \\
\hline
\end{tabular}

Table 11: Outlet 2 Appliance (Lamp) Testing

\begin{tabular}{|c|c|c|}
\hline Outlet 2 Testing & Lamp & \\
\hline & $\begin{array}{c}\text { ONCondition } \\
(\text { 'B') }\end{array}$ & $\begin{array}{c}\text { OFF Condition } \\
(' G ')\end{array}$ \\
\hline Trials & Time(secs) & Time(secs) \\
\hline 1 & 13.6 & 5.7 \\
\hline 2 & 14.6 & 5.5 \\
\hline 3 & 14.8 & 5.5 \\
\hline 4 & 14.2 & 5.1 \\
\hline 5 & 15.1 & 5.9 \\
\hline 6 & 13.8 & 6.1 \\
\hline 7 & 15.2 & 5.2 \\
\hline 8 & 14.1 & 5.1 \\
\hline 9 & 16.2 & 5.6 \\
\hline 10 & 14.2 & 6.5 \\
\hline Average Time & 14.6 & $\mathbf{5 . 6}$ \\
\hline
\end{tabular}

Tables 10 and 11 shows the Outlet 2 Appliance (Charger) Testing and Outlet 2 Appliance (Lamp) Testing. Final test of this lamp can be replicated using the papers: [31,32]. 


\section{CONCLUSION AND RECOMMENDATIONS}

Being able to successfully construct the hardware and create the software, the group was able to achieve their objectives. The device was tested to run for several hours without causing any problems to both the hardware and the software. The group concludes that interfacing the hardware and the software together is the key in the thesis. The project relies on the way they communicate with one another. Although that was one of the hardest parts that the group had encountered, the results turned out to be exemplary. The PIC microcontroller was able to accept the message coming from the user and send a logic $0(0 \mathrm{~V})$ or a logic $1(5 \mathrm{~V})$ that switched the relays. From the gathered data, it takes less than a minute to control the appliances, whether to switch it off or on. Furthermore, the time it takes for the device to switch the appliances merely depends on the distance. The factor that delays the system's coverage of the signal of the GSM and the handheld device. Under low reception circumstance, the GSM module either receives the message from the mobile application later than the usual time or never receives it at all. When the message is received later, the sequencing of the time delay in the program gets messed up thus the program may not run properly.

There are lots of recommendations regarding on how to improve the thesis's hardware and software. For the hardware, it is better to create a more portable or handy prototype to be less bulky and heavy. Though constructing a smaller device requires a smaller circuit design. Hence, as much as possible, simplify the circuit connections and contain all the PCBs including the GSM in only one module. Also, adding more outlets in the device means more appliances can be controlled therefore it is more effective. Aside from the outlets, the device can further be improved by adding switches where the user can manually switch the appliances without using SMS or pulling out the plugs. Another recommendation is to add the ability of the user to check how many hours a certain appliance has been running for them to check the possibility of high electric consumption. We also recommend for the integration of our application to another operating system such as for Apple and for Windows phones. Also, another recommendation is to enable multiple users connecting to the same appliances in a home. It can be an advantage for parents who want to look after their child left at home. For the software, it is recommended to add Wi-fi connectivity to the application since signal reception is not always strong and/or available, though Wi-fi is also not always available by adding both, it can increase the application's reliability. For both hardware and software, it is recommended to use a device that can control the intensity of the appliance useful for electric fans, air conditioning units, refrigerators and some light bulbs without tampering in any of the appliances' circuitry.

\section{REFERENCES}

[1] T. Shimada and L. Van Wassenhove, "Closed-loop supply chain activities in Japanese home appliance/personal computer manufacturers: A case study." International Journal of Production Economics. Vol. 212, pp. 259-265, 2019. https://doi.org/10.1016/j.ijpe.2016.11.010

[2] J. Chou and N. Truong, "Cloud forecasting system for monitoring and alerting of energy use by home appliances." Applied Energy. Vol. 249, pp. 166-177, 2019. https://doi.org/10.1016/j.apenergy.2019.04.063

[3] R. Baburske, F. Niedernostheide, H. Schulze, R. Bhojani, J. Kowalsky and J. Lutz, "Unified view on energy and electrical failure of the short-circuit operation of IGBTs." Microelectronics Reliability. Vol. 88-90, pp. 236-241, 2018. https://doi.org/10.1016/j.microrel.2018.06.091

[4] X. Xiao, P. Fu, Q. Li, G. Hu and Y. Jiang, "Modeling and Validation of SMS worm propagation over social networks.” Journal of Computational Science. Vol. 21, No. 1, pp. 132-139, 2017. https://doi.org/10.1016/j.jocs.2017.05.011

[5] N. Moller, L. Andersen, L. Hansen and C. Jensen, "Can pecuniary and environmental incentives via SMS messaging make households adjust their electricity demand to a fluctuating production." Energy Economics. Vol. 80, pp. 1050-1058, 2019. https://doi.org/10.1016/j.eneco.2019.01.023

[6] M. Aiad and P. Lee, "Energy disaggregation of overlapping home appliances consumptions using a cluster splitting approach." Sustainable Cities and Society. Vol. 43, pp. 487-494, 2018. https://doi.org/10.1016/j.scs.2018.08.020

[7] Joohwan Park, S. Han, Jungchul Park, Jaehyun Park, J. Kwahk, M. Lee and D. Jeong, "Development of a web-based user experience evaluation system for home appliances" International Journal of Industrial Ergonomics. Vol. 67, pp. 216-228, 2018. https://doi.org/10.1016/j.ergon.2018.05.017

[8] O. Mirzaei, J. De Fuentes, J. Tapiador and L. Gonzales-Manzano, "ANDRONET: An adaptive android obsufication detector." Future Generation Computer Systems. Vol. 90, No. 1, pp. 240-261, 2019. https://doi.org/10.1016/j.future.2018.07.066

[9] A. Kabakus, and I. Dogru, "An in depth analysis of Android Malware using hybrid techniques." Digital Investigation. Vol.24, Nos. 1, pp. 25-33, 2018. https://doi.org/10.1016/j.diin.2018.01.001

[10] M. Gullo, K. Irvine, G. Feeney and J. Connor, "Short message service (SMS) reminders improve treatment attendance in alcohol dependence but are less effective for patients high in impulsivity." Addictive Behaviors. Vol. 87, pp. 97-100, 2018. https://doi.org/10.1016/j.addbeh.2018.06.025

[11] D. Suleiman and G. Al-Naymat, "SMS spam detection using H2O framework." Procedia Computer Science. Vol. 113, pp. 154-161, 2017. https://doi.org/10.1016/j.procs.2017.08.335 [12]V. Thakur and S. Mangla, "Change management for sustainability: Evaluating the role of human, operational 
and technological factors in leading Indian firms in home." Journal of Cleaner Production. Vol. 213, pp. 847-862, 2019.

https://doi.org/10.1016/j.jclepro.2018.12.201

[13] J. Cravioto, R. Yasunaga and E. Yamasue, "Comparative analysis of average time of use of home appliances." Procedia CIRP. Vol. 61, pp. 657-662, 2017.

https://doi.org/10.1016/j.procir.2016.11.248

[14] N. Alotaibi, "An Efficient Technique for Reducing Transmission Energy of Sensor Node to Enhance the Lifetime of the WSN's." International Journal of Advanced Trends in Computer Science and Engineering (IJATCSE). Vol. 8, No. 2, pp. 108-111, 2019.

https://doi.org/10.30534/ijatcse/2019/02822019

[15]A. Africa, "A Rough Set-Based Expert System for diagnosing information system communication networks." International Journal of Information and Communication Technology. Vol. 11, No. 4, pp. 496-512, 2017. https://doi.org/10.1504/IJICT.2017.10008315

[16] A. Africa and M. Cabatuan, "A Rough Set Based Data Model for Breast Cancer Mammographic Mass Diagnostics." International Journal of Biomedical Engineering and Technology. Vol. 18, No. 4, pp.359-369, 2015.

https://doi.org/10.1504/IJBET.2015.071010

[17] R.C. Gustilo, E. Dadios, "Optimal Control of Prawn Aquaculture Water Index Quality using Artificial Neural Networks." Proceedings of the 2011 IEEE $5^{\text {th }}$ International Conference of Cybernetics and Intelligent Systems. 2011 https://doi.org/10.1109/ICCIS.2011.6070339

[18] E. Jimenez, K. Matsuzaki and R.C. Gustilo "Fuzzy Based intelligent short listing process for human resource job recruitment procedures." International Journal of Engineering and Technology (UAE). Vol. 7, No. 4, pp. 229-233, 2018.

[19] A. Africa, "A Logic Scoring of Preference Algorithm using ISO/IEC 25010:2011 for Open Source Web Applications Moodle and Wordpress." ARPN Journal of Engineering and Applied Sciences. Vol. 13, No.15, pp. 4567-4571. 2018.

[20] L. Zhang, Z. Chen, J. Su and J. Li "Data mining of New Energy Materials from Structure Databases" Renewable and Sustainable Energy Reviews. Vol. 107, No. 1, pp.554-567, 2019. https://doi.org/10.1016/j.rser.2019.03.036

[21] J. Guan, Z. Wei, and I. You "GRBC Based Network Security Functions Placement Schemes in SDS for 5G Security." Journal of Network and Computer Applications. Vol. 114, No. 1, pp. 48-56, 2018. https://doi.org/10.1016/j.jnca.2018.03.013

[22]C. Dong and L. Zhao, "Sensor Network Security Defense Strategy based on attack graph and improved binary PSO." Safety Science. Vol. 117, Nos, 1, pp. 81-87, 2019.

https://doi.org/10.1016/j.ssci.2019.04.007
[23] N. Miloslavskaya, "Developing a Network Security Intelligence Center." Procedia Computer Science. Vol. 145, No. 1, pp.359-364, 2018. https://doi.org/10.1016/j.procs.2018.11.085

[24] P. Hanpinitsak, K. Saito, J. Takada, M. Kim and L. Materum, "Clustering Method based on scatterer locations for indoor dynamic MIMO channels" 2016 10th European Conference on Antennas and Propagation, EuCAP 2016. 2016. https://doi.org/10.1109/EuCAP.2016.7481586

[25] R.C. Gustilo, E. Dadios, E. Calilung and L. Lim, "Neuro-Fuzzy Control Techniques for Optimal Water Quality Index in a Small Scale Tiger Prawn Aquaculture Setup" Journal of Advanced Computational Intelligence and Intelligent Informatics. Vol. 18, Nos. 5, pp.805-811, 2014. https://doi.org/10.20965/jaciii.2014.p0805

[26] S. Brucal, A. Africa and E. Dadios, "Female Voice Recognition using Artificial Neural Networks and MATLAB Voicebox Toolbox." Journal of Telecommunication, Electronic and Computer Engineering. Vol. 10, Nos. 1-4, pp. 133-138, 2018.

[27]P. Loresco and A. Africa, "ECG Print-out Features Extraction Using Spatial-Oriented Image Processing Techniques." Journal of Telecommunication, Electronic and Computer Engineering. Vol. 10, Nos. 1-5, pp. 15-20, 2018.

[28]L. Villanueva and R.C. Gustilo, "Artificial neural network based antenna sensitivity assignments for chaotic Internet Service Provider network architecture." International Journal of Engineering and Technology (UAE). Vol. 7, No. 2, pp. 14-17, 2018. https://doi.org/10.14419/ijet.v7i2.3.9958

[29] D. Ahamad, M. Akhtar and S. Hameed, "A Review and Analysis of Big Data and MapReduce." International Journal of Advanced Trends in Computer Science and Engineering (IJATCSE). Vol. 8, No. 1, pp. 1-3, 2019. https://doi.org/10.30534/ijatcse/2019/01812019

[30]A. Africa and C. Uy, "Development of a Cost-Efficient Wastebin Management System with Mobile Monitoring and Tracking." International Journal of Advanced Trends in Computer Science and Engineering (IJATCSE). Vol. 8, No. 2, pp. 319-327, 2019. https://doi.org/10.30534/ijatcse/2019/35822019

[31] M. Ibbini, and A. Adawi, "Analysis and Design of a Maximum Power Point Tracker for a Stand-Alone Photo Voltaic System Using Simscape.” International Journal of Advanced Trends in Computer Science and Engineering (IJATCSE). Vol. 8, No. 1, pp. 54-56, 2019. https://doi.org/10.30534/ijatcse/2019/09812019

[32] A. Vandana, R. Mohan, A. Abdul, B. Sujatha, and B. Nanda Kishore, "Fault detection in three phase transmission line using Wavelet Transform algorithm." International Journal of Advanced Trends in Computer Science and Engineering (IJATCSE). Vol. 8, No. 1, pp. 82-84, 2019. 